\title{
Christine Ferlampin-Acher, Perceforest et Zéphir: propositions autour d'un récit arthurien bourguignon
}

\author{
Maria Colombo Timelli
}

\section{(2) OpenEdition}

1 Journals

\section{Édition électronique}

URL : https://journals.openedition.org/studifrancesi/4607

DOI : 10.4000/studifrancesi.4607

ISSN : 2427-5856

Éditeur

Rosenberg \& Sellier

\section{Édition imprimée}

Date de publication : 1 avril 2012

Pagination : 124-125

ISSN : 0039-2944

\section{Référence électronique}

Maria Colombo Timelli, « Christine Ferlampin-Acher, Perceforest et Zéphir: propositions autour d'un récit arthurien bourguignon ", Studi Francesi [En ligne], 166 (I | LVI) | 2012, mis en ligne le 30 novembre 2015, consulté le 19 novembre 2021. URL : http://journals.openedition.org/studifrancesi/4607 ; DOI :

https://doi.org/10.4000/studifrancesi.4607

Ce document a été généré automatiquement le 19 novembre 2021.

\section{(c) $(1) \odot$}

Studi Francesi è distribuita con Licenza Creative Commons Attribuzione - Non commerciale - Non opere derivate 4.0 Internazionale. 


\title{
Christine Ferlampin-Acher, Perceforest et Zéphir: propositions autour d'un récit arthurien bourguignon
}

\author{
Maria Colombo Timelli
}

\section{RÉFÉRENCE}

CHRISTINE FERLAMPIN-ACHER, Perceforest et Zéphir: propositions autour d'un récit arthurien bourguignon, Genève, Droz («Publications Romanes et Françaises», CCLI), 2010, pp. 476.

1 Après une fréquentation qui dure depuis une bonne vingtaine d'années et dont rend compte la bibliographie réunie sous son nom aux pp. 203-206, Christine FerlampinAcher fait le point sur une question non secondaire concernant Perceforest, à savoir l'époque et le milieu de sa rédaction.

2 Son hypothèse - qu'elle a l'honnêteté de proposer toujours en tant que telle et de ne jamais transformer en affirmation positive - est que ce roman a été composé, plutôt que vers 1340 comme il est couramment admis, dans la Bourgogne de Philippe le Bon vers 1450. Une première partie (Dater 'Perceforest', pp.15-86, et 'Perceforest' et la Bourgogne de Philippe le Bon, pp. 87-216) réunit un certain nombre d'indices à l'appui; d'une part, les éléments externes au texte, à savoir la conservation de témoins très concentrés dans le temps (quatre manuscrits exécutés entre 1459 et 1477) et dans l'espace, culturel sinon strictement géographique: la Bourgogne de Philippe le Bon, Louis de Bruges, Jacques d'Armagnac, l'Angleterre d'Edouard Iv. D'autre part, et là les choses se font plus délicates et plus compliquées, quelques arguments internes au récit lui-même: la coprésence d'Alexandre et Arthur, figures très à la mode dans la Bourgogne ducale, l'insertion et le traitement des tournois, dont l'invention est attribuée à Alexandre, les spectacles pouvant renvoyer à des banquets et entrées 
royales, les scènes ressemblant à des pièces de théâtre (farces et mystères), l'onomastique et la toponymie (celle-ci renvoyant plus à une Bourgogne rêvée que réaliste, et poussée vers le Nord).

3 La deuxième partie se concentre sur Zéphir, personnage-clef de l'histoire (Zéphir, $d u$ 'luiton' à la conception virginale du Christ, pp. 263-408): loin d'être une figure anecdotique, ce personnage tient du luiton, de l'ange déchu, du 'trickster', du genius loci, de l'ange gardien et du diable de théâtre; figure polymorphe et métamorphique, il s'installe, selon C.F.-A. «à la croisée du folklore, des savoirs naturels et des questionnements théologiques» (p.398), dans un roman qui célèbre en la préfigurant la naissance du Christ et qui annonce la christianisation de la Bretagne.

Un dernier chapitre a pour titre Essai de reconstitution et hypothèses (pp. 409-426); tout en reprenant les arguments déjà proposés et soumis à discussion, C.F.-A. avance une dernière hypothèse, à savoir l'idée que David Aubert pourrait être non seulement le copiste des mss. Arsenal 3483-3494, exécutés en 1459-1460, mais bien l'auteur de Perceforest; dans ce cas, sa minute (et non pas la «grosse», comme il est dit p. 415), qui a appartenu à la bibliothèque de Philippe le Bon, serait en même temps la copie la plus ancienne et l'original du roman. L'hypothèse, séduisante, ne parvient cependant pas à convaincre, surtout à cause des pièces en vers qui se lisent dans les manuscrits $A$ et $B$, mais qui sont réécrites en prose dans la copie de D. Aubert justement (cf. ici même, p. 46).

5 Certes, l'auteur de Perceforest n'a pas facilité la tâche à ses lecteurs contemporains, confrontés à des allusions et à une dose importante d'implicite, ainsi qu'à des éléments qu'il est difficile de ramener à une vision unique et cohérente: mais on tient là sans doute une des raisons de son succès dans les milieux curiaux de la fin du Moyen Âge, passionnés par les récits longs et enchevêtrés et par les histoires des origines.

6 C'est sur la base d'une connaissance aussi vaste qu'approfondie de la littérature médiévale et du milieu bourguignon que C.F.-A. a pu aborder un sujet difficile et passionnant: on verra avec intérêt la riche bibliographie qui occupe les pp. 431-457. Il pourra donc sembler ingénéreux de lui adresser deux petits reproches. D'une part, on relève un nombre assez élevé de coquilles, souvent pour des noms propres (Jane Taylor se voit attribuer un prénom français, Jeanne, p. 16; Tania Van Hemelryck voit doubler fréquemment son -m-, Luigi Pulci devient Pucci p. 407), mais aussi des fautes qu'une relecture attentive aurait permis de supprimer (deux seuls exemples: en temps que tel, p. 145, à lire évidemment en tant que tel; et sur un autre plan, Gédeon, sic, transformé en héros de l'Antiquité, p. 141).

7 D'autre part, cette vaste réflexion ne coïncide pas toujours avec une véritable synthèse des travaux antérieurs de l'Auteure: les redites sont nombreuses, ce qui peut être dû justement à la reprise d'articles déjà publiés. On signalera aussi que pour un certain nombre d'articles donnés comme sous presse dans les notes en bas de page on trouvera les références complètes dans la bibliographie.

8 Ayant quelque peu fréquenté moi-même, non pas Perceforest, mais la littérature bourguignonne, j'apporterai trois petites pierres à l'édifice complexe bâti par C.F.-A. Premièrement, en soulignant qu'une étude des proverbes dans le texte reste à faire, elle cite une exclamation de Perceforest: J'ay ö̈ dire: Va ou tu peulz, meurs ou tu doiz (p. 252), en ajoutant que celle-ci est attestée «dans une pièce morale du $\mathrm{Xv}^{\mathrm{e}}$ siècle»; ce proverbe est aussi un des derniers du recueil alphabétique réuni par Jean Miélot autour de 1456 (éd. dans «Romania», 125, 2007, pp.370-399, n. 331). Deuxièmement, à propos de la 
géographie septentrionale du récit, on rappelle un renvoi à la Norvège (p. 221); or, dans le ms. A de Jean d'Avennes (deuxième moitié du Xve siècle, éd. A.M. Finoli, Milan, 1979, ch. XXV, 22), les hérauts chargés d'annoncer un tournoi se rendent jusqu'en «Norwegue»: il s'agit manifestement d'une lectio difficilior que le copiste de $B$ remplace par «Overgne», mais qui est corroborée par le témoignage de Georges Chastellain, rappelant justement l'intérêt du roi de Norvège pour un pas d'armes lancé en Bourgogne (éd. citée, p. XLV). Et enfin, le préambule de la rédaction B du Pas du Perron Fée (avril 1462, éd. en cours par Michelle Szkilnik) donne une liste des lectures de Philippe de Lalaing, promoteur du Pas: parmi les preux évoqués, on ne sera plus surpris de trouver Perceforest lui-même. 